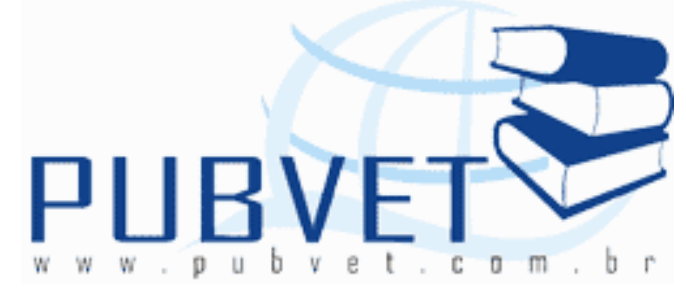

PUBVET, Publicações em Medicina Veterinária e Zootecnia.

Disponível em: <https://doi.org/10.31533/pubvet.v02n10a414>.

\title{
Ionóforos e tampões na alimentação de ruminantes
}

Tadeu Silva de Oliveira ${ }^{1}$, Gustavo Chamon de Castro Menezes ${ }^{1}$, Édina de Fátima Aguiar², Maria Angélica Chamon de Menezes ${ }^{3}$

1Zootecnista, Mestrando em Nutrição e Produção de Ruminantes/UFV

2Zootecnista, Mestrando em Nutrição e Produção de Monogástrico/UFVJM ${ }^{3}$ Estudante de Zootecnia/UFV

\section{Resumo}

Um dos métodos para reduzir custos com a alimentação, na produção animal, é através do uso de aditivos alimentares. Os efeitos principais dos aditivos alimentares são aumentar a eficiência alimentar e ou ganhos diários. Alguns aditivos têm outros benefícios que incluem redução da incidência de acidose, e coccidioses, enquanto outros suprimem o estro, reduzem abscessos e podridão de cascos. Dentre os aditivos liberados para o uso no Brasil e utilizados para ruminantes tem-se: tampões, ionóforos, antibióticos não ionóforos, enzimas fibrolíticas, leveduras, lipídeos, própolis, entre outros. Alguns desses não proporcionam um bom resultado em bovinos de corte mantidos a pasto, sendo de pouca utilização, é o caso dos tampões e das leveduras, que tem seu uso mais amplo na bovinocultura de leite e em sistemas de produção que utilizam dietas ricas em grãos. Outros ainda, estão em fase de pesquisa, exemplos seria o lipídeo e a própolis, utilizados como manipuladores ruminais. A 
manipulação da fermentação ruminal com a utilização de ionóforos, tem como principais objetivos aumentar a formação de ácido propiônico, diminuir a formação de metano (responsável pela perda de $2 \%$ a $12 \%$ da energia do alimento) e reduzir a proteólise e desaminação da proteína dietética no rúmen. Os tampões podem promover melhoria na produtividade e evitar problemas metabólicos no animal por neutralizar o excesso de ácidos produzidos no rúmen em situações onde os sistemas tamponantes do próprio animal, principalmente o fluxo salivar são inadequados. Os ionóforos melhoram a eficiência do metabolismo de energia alterando os tipos de ácidos graxos voláteis produzidos no rúmen e diminuindo a energia perdida pelo metano durante essa fermentação, melhorando o desempenho animal. $O$ uso de aditivos tamponantes ou alcalinizantes é recomendado quando não é possível proporcionar uma fermentação ruminal adequada, somente com o manejo correto da alimentação animal.

\section{Abstract}

One of the methods to reduce costs with the feeding, in the animal production, is through the use of addictive alimentary. The main effects of the addictive ones alimentary are to increase the alimentary efficiency and or won diaries. Some addictive ones have other benefits that include reduction of the incidence of acidosis, and coccidioses, while others suppress the estro, they reduce abscesses and rottenness of skulls. Among the addictive ones liberated for the use in Brazil and used for ruminant it is had: lids, ionóforos, antibiotics non ionóforos, enzymes fibrolíticas, yeasts, lipídeos, própolis, among others. Some of those they don't provide a good result in bovine of cut maintained to pasture, being of little use, it is the case of the lids and of the yeasts, that he/she has your wider use in the bovinocultura of milk and in production systems that use rich diets in grains. Other still, they are in research phase, examples would be the lipídeo and the própolis, used as manipulators you ruminate. The manipulation of the fermentation ruminal with the ionóforos use, 
has as objective principal to increase the formation of acid propiônico, to reduce the formation of methane (responsible for the loss of $2 \%$ to $12 \%$ of the energy of the food) and to reduce the proteólise and desaminação of the dietary protein in the rúmen. The lids can promote improvement in the productivity and to avoid metabolic problems in the animal for neutralizing the excess of acids produced in the rúmen in situations where the systems tamponantes of the own animal, mainly the flow to salivate they are inadequate. The ionóforos improve the efficiency of the metabolism of energy altering the types of acids volatile graxos produced in the rúmen and reducing the lost energy for the methane during that fermentation, improving the animal acting. The use of addictive tamponantes or alcalinizantes is recommended when it is not possible to provide a fermentation appropriate ruminal, only with the correct handling of the animal feeding.

\section{Introdução}

Um dos métodos para reduzir custos com a alimentação, na produção animal, é através do uso de aditivos alimentares. Aditivo, pelo "decreto 76.986 de 6 de janeiro de 1976" do Ministério da Agricultura, Pecuária e Abastecimento, é: "Substancia intencionalmente adicionada ao alimento, com finalidade de conservar, intensificar ou modificar suas propriedades, desde que não prejudique seu valor nutritivo, como antibióticos, corantes, conservadores, antioxidantes e outros."

Os efeitos principais dos aditivos alimentares são aumentar a eficiência alimentar e ou ganhos diários. Alguns aditivos têm outros benefícios que incluem redução da incidência de acidose, e coccidioses, enquanto outros suprimem o estro, reduzem abscessos e podridão de cascos. Dentre os aditivos liberados para o uso no Brasil e utilizados para ruminantes tem-se: tampões, ionóforos, antibióticos não ionóforos, enzimas fibrolíticas, leveduras, lipídeos, própolis, entre outros. Alguns desses não proporcionam um bom resultado em bovinos de corte mantidos a pasto, sendo de pouca utilização, é o caso dos 
tampões e das leveduras, que tem seu uso mais amplo na bovinocultura de leite e em sistemas de produção que utilizam dietas ricas em grãos. Outros ainda, estão em fase de pesquisa, exemplos seria o lipídeo e a própolis, utilizados como manipuladores ruminais (Oliveira, 2005).

Desde 1991 os chamados ionóforos são proibidos na União Européia (UE) para utilização na pecuária leiteira e em 2006 na pecuária de corte. A mesma classe de antibióticos está proibida para uso em vacas leiteiras nos Estados Unidos. O Brasil ainda não restringe a utilização de ionóforos na pecuária leiteira ou de corte, mas é hora de começar a pensar seriamente no assunto, pois ainda que não participe do comércio internacional de leite é um importante exportador de carne bovina. Apesar dos ionóforos serem utilizados em baixas dosagens, a administração contínua nas vacas de leite e gado de corte deixa resíduos no leite e na carne respectivamente. Isso significa que há possibilidade de resistência a antibióticos usados na saúde humana, principalmente em crianças, maiores consumidores das proteínas do leite e que ainda estão desenvolvendo seu sistema imunológico. Na carne bovina, o acúmulo de resíduos durante anos pode proporcionar resistência de determinadas bactérias no organismo humano.

\section{Ionóforos}

Os ionóforos são assim chamados por causa de sua propriedade transportadora de íons, possuindo capacidade de formar complexos lipossolúveis com cátions e mediar seu transporte através da membrana lipídica (Pressman, 1968).

Os ionóforos são tipos de antibióticos que, seletivamente, deprimem ou inibem o crescimento de microorganismos do rúmen. Eles são produzidos por diversas linhagens de Streptomyces, e pelo menos 74 deles foram descobertos depois da lasalocida que é um tipo de ionóforo, em 1951. Os ionóforos foram inicialmente utilizados como coccidiostáticos para aves, mas a partir da década de 1970 começaram a ser utilizados na dieta de ruminantes. A lasolacida e a 
monensina têm sido utilizadas no Brasil como promotor de crescimento em confinamento (Nicodemo, 2001). Existem mais de 120 ionóforos descritos, mas somente a monesina, lasalocida, salinomicina e laidomicina são aprovados para o uso em dietas de ruminantes (Nagaraja et al., 1997). No Brasil, somente a monesina e a lasalocida são liberados no uso para ruminantes.

A manipulação da fermentação ruminal com a utilização de ionóforos, tem como principais objetivos aumentar a formação de ácido propiônico, diminuir a formação de metano (responsável pela perda de $2 \%$ a $12 \%$ da energia do alimento) e reduzir a proteólise e desaminação da proteína dietética no rúmen. Alguns aditivos podem alcançar parte desses efeitos, aumentando a eficiência produtiva (Nicodemo, 2001).

\section{Modo de Ação}

Os ionóforos aumentam o desempenho animal, principalmente devido às alterações na fermentação ruminal. Algumas das respostas dos desempenhos podem ocorrer por mudanças metabólicas que não envolvem alterações na fermentação ruminal (efeitos pós-ruminais). São altamente efetivos contra bactérias Gram-positivas e exibem pouca ou nenhuma atividade contra bactérias Gram-negativas. As bactérias Gram-negativas possuem uma camada lipídica externa que contém porina (canais de proteína), com um tamanho limite de, aproximadamente 600 Dalton (Da). A maioria dos ionóforos são maiores que $600 \mathrm{Da}$, não passando através das porinas (Nagajara et al, 1997). 


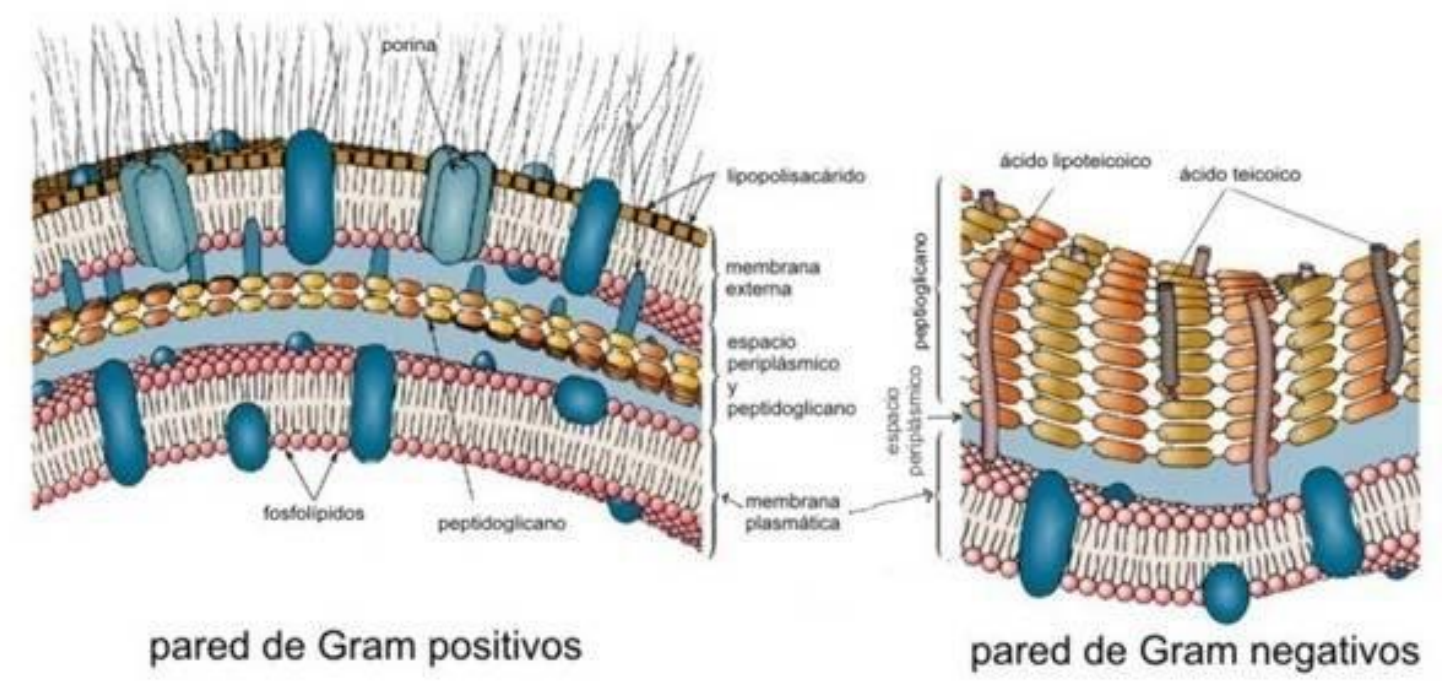

Figura1. Representação esquemática da parede celular de bactérias gram positivas e negativas.

Fonte: http://www.quimicaviva.qb.fcen.uba.ar/v5n2/sanchez.htm

As bactérias Gram-positivas não possuem essa camada externa e a monesina pode penetrar livremente na membrana celular. Entretanto, a presença de membrana externa não é um absoluto critério para resistência, algumas bactérias Gram-negativas são susceptíveis a altas concentrações de ionóforos (Nagajara e Taylor, 1987). A maioria das células expele prótons ativamente (via ATPase) através da membrana celular e mantém o interior mais alcalino. As bactérias mantêm, internamente, concentrações de $\mathrm{K}+$ muito altas, maiores que no meio externo (culturas de $S$. bovis mantêm a concentração de $\mathrm{K}+$ interna cerca de 70 vezes maior que a externa). As concentrações internas altas de $\mathrm{K}+$ são necessárias não só para a síntese de proteína, como também o gradiente de $\mathrm{K}+$ que se forma é importante para tamponar $\mathrm{o} \mathrm{pH}$ intracelular por meio do mecanismo de troca de $\mathrm{K}+/ \mathrm{H}+$. É necessário que o excesso de prótons $(\mathrm{H}+)$ seja expulso da bactéria para que o $\mathrm{pH}$ interno se estabilize. Esse gradiente de $\mathrm{pH}(\mathrm{D} \mathrm{pH})$ cria um gradiente químico de prótons; como o interior da membrana é mais negativo que o exterior, é criado também um potencial elétrico (Dy). D pH e Dy são responsáveis pela formação da força motriz de prótons, que pode ser utilizada 
para importar solutos para dentro da membrana. A monensina desorganiza o transporte de íons segundo o modelo em que um cátion monovalente é trocado por outro durante a passagem pela membrana plasmática. A monensina tem cerca de dez vezes maior afinidade por $\mathrm{Na}+/ \mathrm{H}+$ que por $\mathrm{K}+/ \mathrm{H}+$. Entretanto, o gradiente de $\mathrm{K}+$ é cerca de 25 vezes maior que o gradiente de $\mathrm{Na}+$, tornando o efluxo de $\mathrm{K}+$ via monensina mais favorável que o efluxo de $\mathrm{Na}+$. O efluxo de $\mathrm{K}+$ resulta em acúmulo de $\mathrm{H}+$, levando ao decréscimo no $\mathrm{pH}$ intracelular. Assim, por exemplo, culturas de $S$. bovis mantêm pH interno próximo a 7,08 quando o pH externo é de 6,65 , gerando um potencial prótonquímico de $-26 \mathrm{mV}$. Quando a monensina é adicionada ao meio de cultura, a bactéria parece perder a capacidade de expelir prótons e o interior da membrana passa a ser mais ácido que o ambiente externo. Embora o gradiente elétrico não seja afetado (deve haver compensação da entrada de cátions por meio de saída de cátions ou entrada de ânions), a inversão do pH provoca decréscimo na força motriz de prótons. A redução de $\mathrm{K}+$ intracelular pela adição de monensina levou o gradiente de $\mathrm{K}+$ a apresentar queda para cerca de $1 / 3$ do valor original ( 25 vs. 70 ), ao mesmo tempo em que o gradiente de sódio se elevou. A entrada de $\mathrm{Na}+$ pode ter sido gerada por saída de $\mathrm{H}+$, por causa do menor $\mathrm{pH}$ intracelular. A dissipação do gradiente de $\mathrm{K}+$ deve ter sido apenas parcialmente compensada pelo aumento no gradiente de $\mathrm{Na}+$. A inibição de crescimento observada nas bactérias, provavelmente, devese ao incremento do transporte ativo (dependente de energia) de $\mathrm{H}+$ para fora da célula (Russel, 1987).

A Monensina atua nas trocas de sódio e prótons através do sistema antitransporte em nível de membrana celular microbiana, mas também catalisa trocas de prótons e potássio. Já a lasalocida atua nas trocas de metais mono ou divalentes e prótons pelo sistema anti-transporte (Pressman, 1976). 


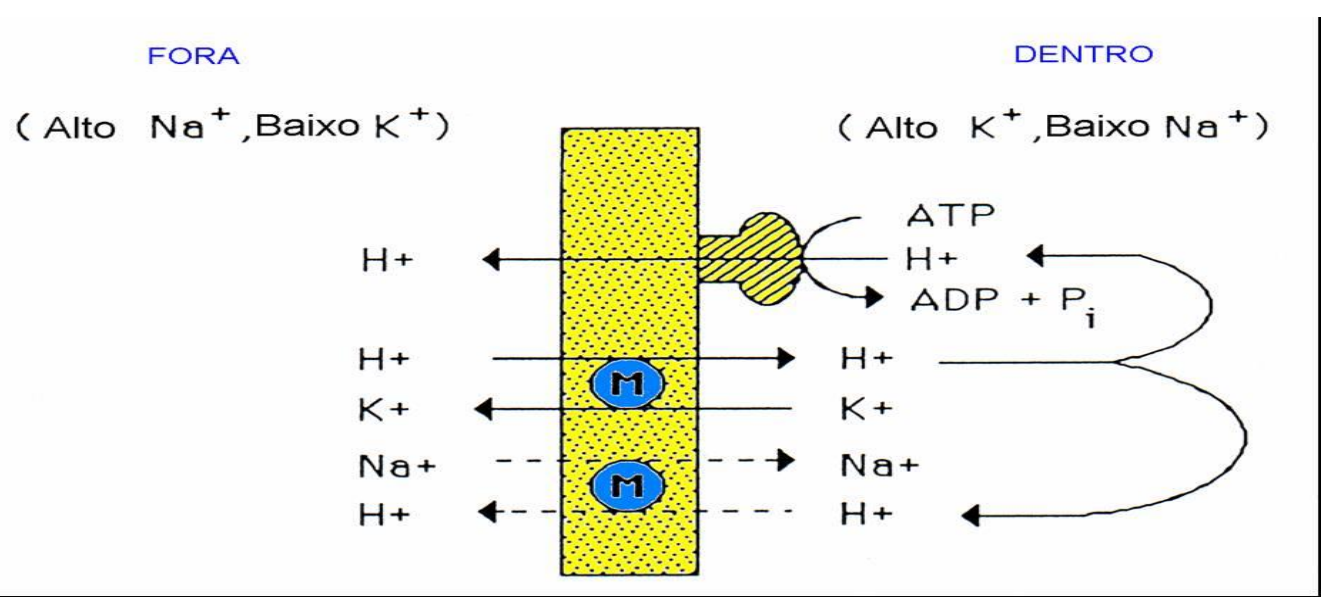

Figura 2. Efeito hipotético da monensina sobre o fluxo de íons de bactérias gram - positivas Streptococcus bovis (Russel e Strobel, 1989).

A maioria dos estudos de mudança da fermentação ruminal associados com ionóforos tem sido feito com monesina ou lasalocida (Chen e Russel, 1989). As ações dos ionóforos sobre o desempenho parecem resultar de uma série de efeitos sobre o metabolismo (Stock e Mader, 1998).

Os ionóforos melhoram a eficiência do metabolismo de energia alterando os tipos de ácidos graxos voláteis produzidos no rúmen (aumento de propionato, redução de acetato e butirato) e diminuindo a energia perdida pelo metano durante essa fermentação. O melhor desempenho animal é resultante de maior retenção de energia durante a fermentação ruminal. Concomitante ao aumento do propionato há uma redução do acetato.

Diminuem a degradação de proteína ruminal e a síntese de proteína microbiana, sem reduzir ou pouco afetando a proteólise, portanto diminuindo a degradação de peptídeos, resultando em menor produção de amônia e maior escape de peptídeos no rúmen (com vantagens equivalentes ao do escape da proteína da fermentação ruminal), sendo absorvidos pela célula como aminoácidos (Tonissi, 2004). Embora essa atividade tenha poucas implicações para bovinos sob dietas com alto teor de grão, os efeitos podem ser significativos para bovinos em crescimento recebendo dieta à base de forrageiras, quando a proteína é suplementada abaixo dos requisitos (Nicodemos, 2001). 
Podem reduzir a incidência de acidose (por meio de aumento no $\mathrm{pH}$ ruminal e inibição de bactérias produtoras de ácido láctico), timpanismo e coccidiose. A redução dessas patologias melhora o desempenho animal. Considerando que os ionóforos são inibidores de bactérias metanogênicas (Chen e Wolin, 1979, apud Oliveira, 2005), a diminuição na metanogênese pode ser atribuída à redução nos precursores ( $\mathrm{H}_{2}$ e formato). $\mathrm{O}$ aumento do propionato pode ser conseqüência do redirecionamento do hidrogênio que seria utilizado na produção de metano.

Níveis elevados de ionóforos na dieta são tóxicos, causando inapetência e, eventualmente, a morte. Os sinais clínicos e lesões não são específicos. 0 diagnóstico preventivo de intoxicação por ionóforos baseia-se na ocorrência de problemas alimentares caracterizados clinicamente por anorexia, diarréia, dispnéia, depressão, recumbência e morte. Não se conhece até o momento antídoto ou tratamento da toxidez induzida por ionóforos, mas é possível que a degeneração celular mediada por peroxidação lipídica possa ser minimizada com a suplementação de vitamina E e selênio (Basaraba et al., 1999).

\section{Monensina}

A monensina é produzida por uma cepa de Streptomyces cinnamonensis e pertence à classe geral de compostos denominados poliéteres (Haddad e Lourenço, 1977).

Esta aumenta a produção de ácido propiônico no rúmen, o que resulta em decréscimo da proporção do ácido acético, mas sem alterar significativamente a produção de ATP. Esse efeito é causado por ação seletiva na população microbiana, diminuindo o número de bactérias gram-positivas. Essas bactérias são produtoras primárias de acetato e butirato, em contrapartida, as gram-negativas têm como produto principal de sua fermentação o propionato (Kone et al., 1989). 
De acordo com Nagaraja et al. (1997) a monensina aumenta a eficiência energética animal em torno de $5 \%$, em virtude da maior produção de propionato, menor formação de metano e aumento na energia retida.

Assumindo que o propionato é essencial para o metabolismo energético dos ruminantes, sua maior disponibilidade contribuirá para diminuir o incremento calórico, poupar aminoácidos normalmente destinados a gliconeogênese e promover, assim, síntese de proteína corporal (Potter et al., 1968).

\section{Efeito da monensina no consumo de alimento e desempenho animal.}

Salles e Lucci (2000) trabalhando com bovinos suplementados com monensina tiveram ganhos $1,6 \%$ maiores, consumiram $6,4 \%$ menos alimentos e utilizaram $7,5 \%$ menos alimento/100 $\mathrm{kg}$ de ganho, do que aqueles alimentados com dietas controle. Lean et al. (1996) afirmaram que o emprego da monensina tem aumentado os ganhos de peso, em novilhas e bovinos de corte, cerca de 5 a $8 \%$ acima dos animais controle.

Quadro 1. Desempenho de bovinos confinados suplementados com Monensina.

Itens

Número de animais

Peso inicial em kg

Peso final em $\mathrm{kg}$

Monensina (mg/cab/dia)

Ganho de peso (kg/cab/dia)

Consumo de MS (kg/dia)

$\mathrm{Kg}$ de MS / kg de ganho

Fonte: Goodrich (1984).
Controle

Monensina

5.696

5.578

284

283

430

432

246

1,09

1,10

8,27

7,73

8,09

7,43 
Schelling (1984) menciona que ruminantes alimentados com dietas ricas em grãos com suplementação de monensina têm ingestão alimentar reduzida em 10,7\%. A ingestão de alimentos diminui à medida que se eleva a concentração de monensina (Goodrich et al. 1984).

Baile et al. (1979) sugerem que, em dietas ricas em concentrado, a diminuição no consumo de alimento foi atribuída ao sabor desagradável da monensina. Contudo, Oliveira et al. (2002a) observaram maior redução no consumo de alimento relacionado à suplementação com monensina à medida que o nível de concentrado $(0,25,50$ e $75 \%)$ na dieta aumentou. Os autores sugerem que, no caso de animais em confinamento, em que o nível de energia (efeito fisiológico) regula o consumo, o aumento da eficiência energética favorece a redução do consumo de alimentos para satisfazer as necessidades nutricionais.

A administração de $200 \mathrm{mg} /$ dia de monesina diminui a proporção de acetato e aumenta a de propionato, e em dietas com forragens a produção de metano diminui rapidamente quando a monesina é suplementada (Thornton e Owens, 1981, apud Tonissi, 2004).

Russel (1987) observou que três espécies de bactérias isoladas do rúmen utilizam somente aminoácidos como fonte de energia, produzindo grande quantidade de amônia, e são sensíveis aos ionóforos. Essas espécies são denominadas de Clostridium sticklandii (linhagem SR), Peptostreptococcus anaerobicus (linhagem C) e Clostridium aminophilum (linhagem F). O fornecimento de monesina causou uma redução de, aproximadamente, 50\% na produção de amônia ruminal, pela diminuição de 10 vezes nas bactérias fermentadoras de aminoácidos e um aumento na proteína bacteriana. As bactérias produtoras de ácido lático são gram-positivas e, portanto sensíveis a monensina reduzindo a possibilidade de acidose lática (Nagaraja et al., 1997). 


\section{Lasalocida}

A lasalocida é produzida por uma cepa de Streptomyces lasaliensis. Provoca alteração na flora microbiana do rúmen, incrementando as bactérias gram-negativas e provocando diminuição acentuada nas gram-positivas, sendo esta modificação responsável pelas alterações na fermentação ruminal (Chen \& Wollin, 1979 apud Oliveira, 2005). Anderson e Nagaraja (1988) registraram alterações provocadas pela lasalocida, principalmente diminuição na proporção molar de acetato e aumento de propionato, sendo esses valores, significativos, ou não, conforme o período de tempo, após o inicio da aplicação do ionóforo. Esta alteração é benéfica, pois o ácido propiônico é energeticamente mais eficiente, além de reduzir as perdas de metano associadas à produção dos ácidos acético e butírico.

Weiss e Amiet (1990) observaram que a lasalocida aumentou a proporção molar de propionato e diminuiu a concentração de butirato, após 28 dias do fornecimento do ionóforo, registrando ainda incremento na proporção molar de propionato e redução na de acetato no sétimo dia após o início da administração da lasalocida. Trabalho realizado por Amaro et al., (2002), não permitiu indicar a aplicação de lasalocida sódica para bovinos, na expectativa de provocar alterações significativas na fermentação ruminal, a saber, nas concentrações de ácidos graxos voláteis, de amônia, e valores de pH do conteúdo do rúmen. Períodos de adaptação de zero a três semanas em nada modificaram os resultados. A lasalocida também foi inoperante nos valores de volume de líquido ruminal e taxa de passagem de líquidos pelo rúmen. Roso (2001) relata que o uso da lasalocida sódica via sal, embora não tenha afetado o ganho de peso dos animais, resultou em incremento na receita líquida/ha, causado pelo aumento numérico da carga animal e o ganho de peso/ha. 


\section{Efeito da lasalocida no consumo de alimento e desempenho animal}

Oliver (1975) observou maior ganho de peso para animais mantidos em capim bermuda (Cynodon sp) que recebiam lasalocida no suplemento. No entanto Nicodemo (2001), fornecendo, respectivamente, monensina associada ao suplemento mineral e lasalocida associada ao suplemento energético, não verificaram influência no ganho de peso, para animais mantidos em pastagem.

Os modificadores ruminais, os quais englobam a monensina sódica e a lasalocida, diminuem os teores de gordura no leite. A sua ação, através da seleção das bactérias ruminais que melhor convertem os alimentos em nutrientes reduzindo a formação de metano e gás carbônico no rumem, tem como conseqüência o aumento na produção de acido propiônico e uma redução do acido acético. Desta forma existe um aumento na produção de leite, porém com níveis menores de gordura (Kone et al., 1989).

Erasmus et al (1999) estudando o desempenho produtivo de vacas leiteiras alimentadas com diferentes concentrações de lasalocida relata uma queda de $6,7 \%$ na IMS. Porém não foram observados efeitos significativos na produção de leite, as médias gerais obtidas foram de $29,8 \mathrm{Kg} / \mathrm{d}$. Decréscimos não significativos na produção $(\sim 7,14)$ foram observados quando os níveis de utilização de lasalocida na dieta atingiram $20 \mathrm{mg} / \mathrm{Kg}$.

A eficiência da produção leiteira ( $\mathrm{kg}$ de leite/ $\mathrm{Kg}$ de IMS) avaliada por Erasmus et al (1999), tendeu a ser mais elevada para os animais suplementados com o ionóforo. Esta elevação na eficiência produtiva pode ser resposta do melhor valor de energia metabólica, imposto pelo ionóforo, além da elevação na produção de propionato, queda nas produções de metano e melhora na digestibilidade da MS. 


\section{Aditivos Tamponantes}

Tamponantes são substâncias usadas com o intuito de diminuir as variações do $\mathrm{pH}$ do trato digestivo, especialmente o rúmen, e mantê-lo em níveis normais. A faixa ideal do $\mathrm{pH}$ para degradação da fibra fica entre $6,2 \mathrm{e}$ 6,8; havendo grande alteração na degradabilidade em valores inferiores (Góes, et al. 2004). Torna-se importante que o pH ruminal se mantenha dentro dessa faixa de normalidade, para que bactérias celulolíticas possam digerir eficientemente a fibra dos alimentos, e também para evitar problemas metabólicos ao animal, como por exemplo, a acidose.

Os tampões podem promover melhoria na produtividade e evitar problemas metabólicos no animal por neutralizar o excesso de ácidos produzidos no rúmen em situações onde os sistemas tamponantes do próprio animal, principalmente o fluxo salivar são inadequados. De acordo com Góes et al. (2004) normalmente o animal em pastejo não apresenta necessidade do uso de tamponantes, pois a pastagem rica em fibra estimula a produção de saliva, rica em tamponantes, portanto são mais utilizados para bovinos em confinamento. A saliva é considerada o mais importante tampão fisiológico do rúmen. O bovino adulto tem a capacidade de produzir entre 100 e 190 litros de saliva por dia com um pH entre 7,9 e 8,6.

Tampões químicos é a combinação entre ácidos fracos e suas respectivas bases. Entretanto, em nutrição de ruminantes, o termo tampão é aplicado livremente e incluem óxidos ou hidróxidos que neutralizam ácidos presentes nos alimentos ou produzidos durante a fermentação ruminal (Erdman, 1988, apud Nagaraja, 1997). Segundo o mesmo autor, o nome mais adequado para tais compostos seriam agentes neutralizantes ou alcalinizantes.

O uso de tampões pode ser benéfico em rações contendo alto teor de grãos, na adaptação de bovinos a novas dietas, no uso de silagem de milho, de grãos com alta umidade ou dietas à base de trigo (Nagaraja, 1997). 
Os verdadeiros tamponantes neutralizam os ácidos com pequena, ou sem alguma, mudança no $\mathrm{pH}$. Por outro lado, os agentes alcalinizantes neutralizam os ácidos, mas também aumentam o $\mathrm{pH}$. $\mathrm{O}$ mesmo autor ressalta ainda que os compostos classificados como tamponantes ruminais seriam o bicarbonato de sódio, bicarbonato de potássio, carbonato de magnésio e bentonita. Um compostos alcalinizante fornecido ao gado leiteiro, seria o óxido de magnésio (Teixeira, 1997).

De acordo com Nagajara et al.(1997), os dois mecanismos mais claramente estabelecidos, em relação a modificação da fermentação ruminal proporcionada pelos tampões, estariam relacionados ao aumento ou a resistência a mudanças do $\mathrm{pH}$ ruminal e ao aumento da taxa fracional de saída do fluido através do orifício reticulo-omasal ou da taxa de diluição ruminal. 0 aumento na taxa de diluição do fluido seria devido ao aumento da osmolaridade, que aumentaria tanto o consumo de água como o influxo através da parede ruminal. A taxa de diluição, como também o $\mathrm{pH}$, modula o balanço e as atividades das espécies microbianas e a susceptibilidade da digestão fermentativa dos substratos.

\section{Tipos de tamponantes e agentes alcalinizantes}

\section{1-Bicarbonato de sódio}

O Bicarbonato de Sódio na "Nutrição Animal" é um composto cristalino usado predominantemente como tamponante ruminal dos bovinos alimentados com altas quantidades de concentrados. Sua fórmula química é $\mathrm{NaHCO}_{3}$. É considerado um tampão "verdadeiro" pelo seu pKa ser bastante próximo do $\mathrm{pH}$ fisiológico adequado do rúmen, por possuir alta solubilidade no rúmen, o que permite rápida diluição no líquido e maior efetividade de ação. Este é um ingrediente alimentar mineral que contém pelo menos 99\% de bicarbonato de sódio. O tipo "Nutrição Animal" foi desenvolvido especialmente para uso agropecuário. O nível de inclusão varia de 0,75 a $1 \%$ 
de $\mathrm{NaHCO}_{3}$ na MS da dieta total, podendo chegar a $1,2 \%$ ou mais no concentrado (Romanelli, 1995).

Quando utilizados em situações corretas, obtêm-se: aumento na concentração de gordura do leite, maior produção de acetato, aumento na quantidade de sólidos totais, síntese de proteína microbiana e produção de leite corrigida para gordura e apresenta redução na produção de propionato e das desordens metabólicas do rebanho, sendo que esta última é o fator de maior importância para a rentabilidade e a eficiência do uso dos tamponantes. Oliveira et al. (1998) confirmam que realmente existem condições especificas em que o bicarbonato de sódio tem melhor atuação, todavia o fato de possibilitar a manutenção do $\mathrm{pH}$ ruminal em condições ideais, possibilita a ingestão adequada de MS pela vaca leiteira. Segundo os mesmos autores, geralmente a ação dos bicarbonatos torna-se evidente em vacas leiteiras de alta produção ou no inicio da lactação. O bicarbonato pode causar o aumento na ingestão de MS, no entanto, nem sempre provoca aumento na produção de leite ou de gordura do leite (tabela 13).

Tabela 13 - Fornecimento de bicarbonato de sódio $\left(\mathrm{NaHCO}_{3}\right)$ e óxido de magnésio ( $\mathrm{MgO}$ ) para vacas leiteiras, alimentadas com $40 \%$ volumoso e $60 \%$ de concentrado.

\begin{tabular}{lllll}
\hline & Controle & $\mathrm{NaHCO}_{3}(1 \%)$ & $\mathrm{MgO}(0,8 \%)$ & $\begin{array}{l}1 \% \mathrm{NaHCO}_{3}+0,8 \% \\
\mathrm{MgO}\end{array}$ \\
\hline Consumo de MS kg/dia & 18,6 & 19,8 & 19,8 & 19,6 \\
Produção de leite kg/dia & 34,6 & 35,5 & 35,2 & 33,4 \\
Gordura no leite \% & 2,326 & 3,78 & 3,96 & 4,16 \\
pH ruminal & 6,17 & 6,43 & 6,46 & 6,34 \\
Acetato \% molar & 53,0 & 59,2 & 59,6 & 59,9 \\
Propionato \% molar & 28,2 & 21,6 & 21,2 & 22,5 \\
Butirato \% molar & 12,9 & 12,9 & 13,6 & 12,8 \\
\hline
\end{tabular}

Fonte: Adaptado de Eroman et al. (1982). 


\section{2-Óxido de Magnésio}

Este é um dos agentes mais utilizados atualmente, sendo utilizado como fonte de Magnésio (54\%) e como um agente alcalinizante.

Um grande agente alcalinizante ou neutralizante, cuja função é elevar o $\mathrm{pH}$. As recomendações indicam 0,3 a 0,5\% na MS, ou 50 a 90g/dia. Pode, no entanto ser misturado ao $\mathrm{NaHCO}_{3}$ na proporção $1: 3$, e a mistura ser fornecida a $1,25 \%$ da MS (Romanelli, 1985).

Tamponantes combinados com o óxido de magnésio aumentaram o volume ruminal e o desaparecimento da digesta. Eroman et al. (1982) afirmam que a suplementação de $\mathrm{MgO}$ na dieta com relação 40 : 60 de volumoso e concentrado aumentou o $\mathrm{pH}$ ruminal, dados esses que podem ser verificados na tabela 13 (acima).

O óxido de magnésio é normalmente utilizado como tampão, mas na realidade ele é um agente alcalinizante, devido a sua capacidade de neutralizar ácidos. O óxido de magnésio não tem seu pKa definido e tende a ser relativamente insolúvel em água, embora seja muito efetivo na elevação do $\mathrm{pH}$ ruminal, no aumento da gordura secretada no leite e na elevação do consumo de alimentos (Nagaraja, 1997).

\section{3-Carbonato de cálcio}

É um grande agente alcalinizante, porém, apresenta restrições quanto ao fornecimento, pois tem baixa solubilidade e deprime o consumo de MS. Como conseqüência, tem pequena e confusa ação sobre o pH e sobre a percentagem de gordura do leite. Tem seu uso questionado, pode ser incluído em 1,2\% da MS da dieta ou 115 a 180g/dia (Romanelli, 1985). 


\section{4-Sesquicarbonato de sódio}

Este produto tamponante é um composto de $\mathrm{NaHCO} 3$ e carbonato de sódio. Estequimetricamente, o sesquicarbonato de sódio contém um mole de carbonato de sódio e um mole de bicarbonato ligado a dois moles de água e é um derivado purificado de um mineral encontrado normalmente na natureza (Nagaraja et al., 1997). Alguns autores têm demonstrado uma eficiência um pouco superior àquela apresentada pelo bicarbonato de sódio. As recomendações têm sido para $1 \%$ na MS dieta ou entre 160 a 300 g/dia (Romanelli, 1985).

\section{Conclusões}

Os ionóforos melhoram a eficiência do metabolismo de energia alterando os tipos de ácidos graxos voláteis produzidos no rúmen e diminuindo a energia perdida pelo metano durante essa fermentação, melhorando o desempenho animal.

O uso de aditivos tamponantes ou alcalinizantes é recomendado quando não é possível proporcionar uma fermentação ruminal adequada, somente com o manejo correto da alimentação animal.

\section{Referencial Bibliográfico:}

AMARO, F.R.; LUCCI, C.S.; CASTRO, A.L. Efeitos de níveis e períodos de adaptação à lasalocida sódica sobre os parâmetros de fermentação ruminal. $R$. Bras. Zootec. vol.31 no.6 Viçosa Nov./Dec. 2002.

ANDERSON, K.L.; NAGARAJA, T.G. Performance and ruminal changes of early weaned calves fed lasalocid. Journal of Animal Science, v.66, p.806-813, 1988.

BAILE, C.A. et al. Feeding behavioral changes of cattle during introduction to monensin with roughage or concentrate diets. Journal of Animal Science, v.48, p.1501$1508,1979$. 
BASARABA, R.J.; OEHME, F.W.; VORHIES, M.W.; STOKKA, G.L. Toxicosis in cattle from concurrent feeding of monensin and dried distiller's grains contamined with microlide antibiotics. Jornal of veterinary diagnostics investigation, Columbia, $11, \mathrm{n} .1, \mathrm{p}$. 79-86, 1999.

CHEN, G.; RUSSELL, J.B. More monensin-sensitive, ammonia-producing bacteria from the rumen. Applied and Environmental Microbiology, v.55, p.1052-1057, 1989.

ERASMUS, L. J.; SMITH, I.; MULLER, A.; O'HAGAN, D. Effects of lasalocid on performance of lactating dairy cows. Journal of Dairy Science, Champaign, v. 82, n. 8, p. 1817-1823, 1999.

EROMAN, R. A.; HEMKEN, R. W.; BULL, L. S. Dietary sodium bicarbonate and magnesium oxide for early postpartum lactating dairy cows : effects on production, acid-base metabolism, and digestion. Journal of dairy science, Champaign, v. 65, n. 7, p. 712-731, May. 1982.

GÓES, B.; TONISSI, R.H. Leveduras e enzimas na alimentação de ruminantes. Cad. Tec. Vet. Zootec., n.43, p.46-66, 2004.

GOODRICH, R.D., GARRETT, J.E., GAST, D.R. 1984. Influence of monensina on the performance of cattle. Journal Animal Science, 58:1484-1498.

HADDAD, C.M., LOURENÇO JR., J.B. 1977. Monensina: um novo aditivo na alimentação de ruminantes. Zootecnia, 15(3):171-181.

KONE, P., MACHADO, P.F., COOK, R.M. 1989. Effect of the combination of monensin and isoacids on rumen fermentation in vitro. Journal Dairy Science, 72(10):2767-2771.

LEAN, I.J., WADE, L., BECKETT, S.D. 1996. Bovine somatotropin and monensin: emerging technologies. In: Advances in dairy technology, 8:237-253.

Ministério da Agricultura, Pecuária e Abastecimento. Disponível em: http://www.agricultura.gov.br/. Acesso em 10 de maio de 2008.

NAGAJARA, T.G.; NEWBOLD, C.J.; VAN NEVEL, C.J. Manipulation of ruminal fermentation. In: HOBSON, P.N.; STEWART, C.S. (Eds). The rúmen microbial ecosystem. Blackie Academic e Professional, London. P.525-632, 1997.

NAGAJARA, T.G.; TAYLOR, M.B. Susceptibility and ressitence of ruminal bactéria to antimicrobial feed additives. Applied Environmental Microbial, v. 53, p. 1620- 51987.

NICODEMO, M.L.F. 2001, Uso de aditivos na dieta de bovinos de corte. Disponível em http:// www.cnpgc.embrapa.br/publicacoes/doc/. Acesso em 10 de maio de 2008.

OLIVEIRA, M.V.M.; LANA, R.P.; CAMPOS, J.M.S. et al. Desempenho de novilhas leiteiras sob dietas com diferentes níveis de monensina. REUNIÃO ANUAL DA SOCIEDADE BRASILEIRA DE ZOOTECNIA, 39, 2002, Recife. Anais... Recife, 2002a, CD-ROM.

OLIVEIRA, M.V.M.; LANA, R.P.; VALADARES FILHO, S.C. Parâmetros ruminal, sangüíneo e urinário e digestibilidade de nutrientes em novilhas leiteiras recebendo diferentes níveis de monensina. R. Bras. Zootec. vol.34 no.6 Viçosa Nov./Dec. 2005.

POTTER, E.L. et al. Effects of various energy sources upon plasma free amino acids in sheep. Journal of Nutrition, v.95, p.665, 1968. 
Oliveira, T.S., Menezes, G.C.C., Aguiar, E.F. et al. Ionóforos e tampões na alimentação de ruminantes. PUBVET, Londrina, V. 2, N. 43, Art\#414, Out5, 2008.

PRESSMAN, B.C. Ionophorus antibiotics as models for biological transport. Fedding process, 27, p.1283-1288, 1968.

ROMANELLI, V., 1995. Sistemas de alimentação para vacas de alta produção e manipulação ruminal. Cad. Tec. EV-UFMG, BH - MG, n.14, 1995, p. 13-44.

RUSSELL, J.B. A proposed model of monensin action in inhibiting ruminal bacteria growth: effects on ion flux and proton motive force. Journal of Animal Science, v.64, p.1519-1525, 1987.

SALLES, M.S.V.; LUCCI, C.S. Monensina para Bezerros Ruminantes em Crescimento Acelerado. 1. Desempenho. Rev. Bras. Zootec. vol. 29 no. 2 Viçosa Mar./Apr. 2000.

SCHELLING, G.T. 1984. Monensin mode of action in the rumen. Journal Animal Scence., 58(6): 1518-1527.

STOCK, R.; MADER, T. Feed additives for beef cattle. Nebguide G85-761-A. Disponível: site NebGuide (April 1997). URL: http://www.ianr.unl.edu/pubs/beef/g761.htm. Consultado em 10 de maio de 2008.

TONISSI, R.H.; GÓES, B. Aditivos de alimento para bovinos suplementados a pasto. Cad. Tec. Vet. Zootec., n.43, p.34-35, 2004.

WEISS, W.P.; AMIET, B.A. Effect of lasalocid on performance of lactating cows. Journal of Dairy Science, v.73, n.1, p.153-162, 1990. 